\title{
Right upper limb bud triplication and polythelia, left sided hemihypertrophy and congenital hip dislocation, facial dysmorphism, congenital heart disease, and scoliosis: Disorganisation-like spectrum or patterning gene defect?
}

\author{
M A Sabry, Q Al-Saleh, R Al-Saw'an, S A Al-Awadi, T I Farag
}

\begin{abstract}
A Somali female baby with right upper limb triplication, polythelia, left sided hemihypertrophy, congenital hip dislocation, facial dysmorphism, congenital heart disease, and scoliosis is described. It seems that the above described pattern of anomalies has not been reported before. The possible developmental genetic mechanism responsible for this phenotype is briefly discussed.
\end{abstract}

(f Med Genet 1995;32:555-556)

Kuwait Medical Genetics Centre, PO Box 31145, Sulibikhat, 90802 Kuwait M A Sabry

S A Al-Awadi

T I Farag

Paediatric

Department,

Farwanyea Hospital,

Kuwait

Q Al-Saleh

R Al-Saw'an

Corespondence to:

Dr Farag.

Received 9 August 1994

Revised version accepted for

publication 20 February

1995


Several patients with complete or partial duplication of a lower limb have been reported. ${ }^{1-12}$ In this report, we describe the first case of right upper limb triplication, polythelia, left sided hemihypertrophy, and congenital hip dislocation associated with facial dysmorphism, congenital heart disease, and scoliosis.

\section{Case report}

The proband, a female born at term on 7.7.94 with multiple congenital anomalies, was delivered by lower segment caesarian section. Apgar scores were 7 and 8 at one and five minutes. Pregnancy history was unremarkable. The healthy, young, consanguineous parents have six phenotypically normal daughters with no family history of any congenital anomalies. Birth weight was $3360 \mathrm{~g}$, length $50 \mathrm{~cm}$, and head circumference $35 \mathrm{~cm}$. Placental weight was $750 \mathrm{~g}$ and the umbilical cord contained two arteries and one vein. The baby had facial dysmorphism with frontal bossing, left microphthalmia, left microcornea, bilateral iris colobomata, depressed nasal bridge, midfacial hypoplasia, down turned upper lip, high arched palate, short neck, and right torticolis. She had right upper limb triplication including two hypoplastic supernumerary limbs with oligodactyly and an absent thumb on one of them. (fig 1). Right sided polythelia without underlying glandular tissue was present. The right lower limb was shorter than the left with a small right foot and overlapping hypoplastic toes. Two hairy darkly pigmented patches were noted, one on the dorsum of the right foot and the other on the upper part of the back of the forearm of a supernumerary limb. The baby had left hemihypertrophy, scoliosis, and left congenital hip dislocation. The external genitalia were normal female. No CNS, kidney, or other internal organ abnormalities were detected with ultrasound. Skeletal survey showed three right upper limbs including the bones of the shoulder girdle (clavicles and scapulae) and scoliosis (fig 2). Chest $x$ ray showed clear lungs with normal heart size. ECG was normal but echocardiography with Doppler studies showed mild PDA and ASD with a small left to right shunt and mild pulmonary hypertension. Peripheral blood chromosomal study with banding techniques showed a normal female karyotype $(46, \mathrm{XX})$ with no apparent mosaicism. Clinical follow up at the age of 3 months indicated a satisfactory neurodevelopmental status.

Discussion

Limb duplications have traditionally been 


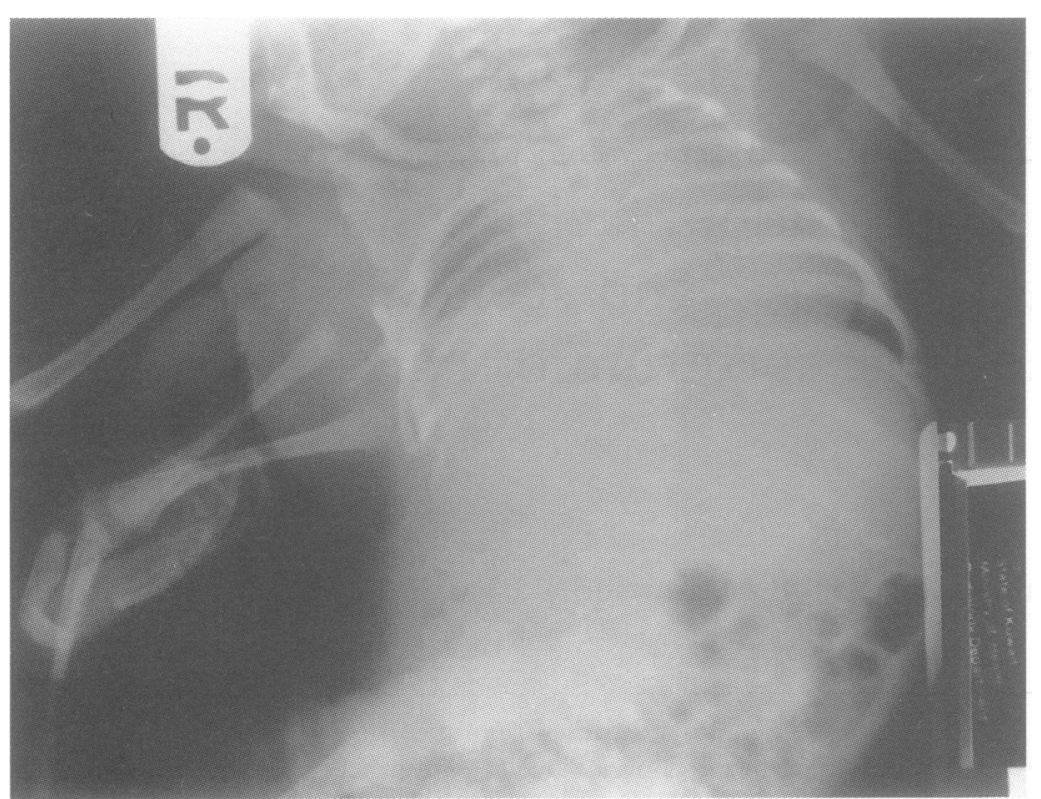

Figure 2 Skeletal survey of proband showing the bones of three right upper limbs and scoliosis.

report may be the result of a de novo somatic mutation of a pleiotropic gene of the patterning families implicated during early embryogenesis, for example, in limb bud mesoderm/ectoderm signal interaction ${ }^{13}$ and in the specification of the branchial region of the vertebrate head. ${ }^{14}$ Alternatively, the present case could fit into the spectrum of the human equivalent of the mouse "Disorganisation locus, DS" (MIM 223200) described in several previous reports. ${ }^{15-17}$

It seems that the presence of two supernumerary right upper limbs, polythelia, left hemihypertrophy, and congenital hip dislocation, associated with facial dysmorphism, congenital heart disease, and scoliosis, has not been described before. However, we cannot claim that the present case represents a new syndrome since phenotypic heterogeneity would be expected among different cases with limb duplications, if the abnormalities were caused by a somatic mutation with consequent mosaic patterns.

1 Walls BH. A unique monstrosity. Am f Obstet 1888;21: 1265-71.

2 Zammit J. Posterior dichotomy: a three legged boy. BMF 1898;i: 1528.

3 Deboo SN. A three legged person. Med Bull Bombay 1943;

4 Smillie IS, Murdoch JH. Man with three legs. F Bone foint Surg (Br) 1952;34:630-5.

Norman WH. A child with three lower extremities. $f$ Bone foint Surg $(\mathrm{Am})$ 1964;46:1755-8.

6 Strivastava KK, Grag LD. Reduplication of bones of lower extremity. $\mathcal{f}$ Bone foint Surg $(\mathrm{Am})$ 1971;53:1445-7.

7 Tanigushi K, Aoki Y, Kurimotgo H, Okamura T. A baby with a third leg. $\mathcal{F}$ Pediatr Surg, 1975;10:143-4.

8 Billett DM, Bear NJ. Partial duplication of the lower limb. 7 Bone foint Surg ( $\mathrm{Am})$ 1978;60:1143-5.

9 Hanley EN, Stanitski CL Incomplete congenital duplication of the lower extremity. $\mathcal{F}$ Bone foint Surg $(A m)$ 1980;62: 479-81.

10 Weisselberg B, Ben-Ami T, Goodman SM. Partial duplication of the lower limb with agenesis of ipsilateral kidney - a new syndrome: report of a case and review of kidney - a new syndrome: report of a cas

11 Takayanagi K. A rare case of caudal duplication. $f$ Pediatr akayanagi K. A rare

12 Chadha R, Dhar A, Malhotra CJ, Taneja SB. An unusual form of caudal duplication. $\mathcal{F}$ Pediatr Surg 1993;28:728-30. form of caudal duplication. F Pediatr Surg 1993;28:728-30.
3 Johnson RL, Riddle RD, Tabin CJ. Mechanisms of limb Johnson RL, Riddle RD, Tabin CJ. Mechanisms
patterning. Curr Opin Genet Dev 1994;4:535-42.

4 Krumlauf R. Hox genes and pattern formation in the branchial region of the vertebrate head. Trends Genet 1993;9 106-12.

15 McKusick VA. Mendelian inheritance in man. 11 th ed. Baltimore: Johns Hopkins University Press, 1994

16 Winter RM, Donnai D. A possible human homologue for the mouse mutant disorganisation. F Med Genet 1989;26: $417-20$

17 Hunmel KP. Developmental anomalies in mice resulting from action of the gene Disorganisation, a semi-dominant lethal. Pediatrics 1959;23:212-21. 